\title{
Correction to "Response: Re: Consider Muscle Disease in Children with Elevated Transaminase"
}

In the above mentioned article, ${ }^{1}$ there was an error in the order of the authors. John M. Westfall, MD was listed as the lead author. The lead author should have been listed as Audrey S. Yee, MD. The electronic version on the Journal of the American Board of Family Medicine website has been corrected. We apologize for the error, and we regret any confusion or inconvenience it may have caused.

\section{References}

1. Yee AS, Wright MA, Yang ML, Parsons JA, Westfall JM. Response: Re: Consider muscle disease in children with elevated transaminase. J Am Board Fam Med 2012;25:938. 